\title{
AS POLÍtICAS EDUCATIVAS PARA O SECTOR DA EDUCAÇÃO DE ADULTOS EM PORTUGAL: AS NOVAS INSTITUIÇÕES E PROCESSOS EDUCATIVOS EMERGENTES ENTRE 1996-2006
}

\author{
BARROS, Rosanna ${ }^{1}$ \\ LOPES, Liliana ${ }^{2}$
}

Este livro de Rosanna Barros constitui parte da investigação desenvolvida no âmbito do seu projecto de doutoramento, essencial para o mapeamento e interpretação multidimensionais do panorama atual do campo da educação e formação de adultos em Portugal.

Nesta obra, o enfoque situa-se nas políticas públicas para a educação de adultos promovidas pelo Estado português entre 1996 e 2006, objecto de uma investigação sociológica comprometida com um posicionamento ético, político e pedagógico filiado na tradição de uma educação de adultos humanista e emancipatória, traduzida numa selecção criteriosa de abordagens teóricas e fontes primárias ancoradas em correntes do pensamento crítico, no que respeita às perspectivas político-filosóficas estruturantes do campo da educação e formação de adultos, denunciando os processos de reconceptualização e despolitização dos conceitos.

O dispositivo metodológico, construído para a operacionalização da pesquisa, assenta numa perspectiva epistemológica tecida entre o paradigma interpretativo-construtivista e o paradigma crítico, em linha de coerência com o posicionamento intelectual e teórico da autora.

Para a análise sociológica dos processos de produção e modelação das políticas educativas para o sector, a autora articula dois vectores fundamentais:

- as dinâmicas de globalização e europeização, introduzindo a perspetiva "pluriescalar" da governação da educação de adultos (BARROS, 2009) à análise sociológica, neste livro focada nas suas dimensões macro e mega; e

- as transformações no lugar e papel do Estado no contexto de emergência de uma "nova educação e formação de adultos" (p. 26), recuperando a análise dos processos pelos quais a ordem económica atual acarreta profundas transformações no poder do Estado e na sua relação com o mercado e a comunidade no que respeita ao sector da educação de adultos.

Na II Parte da obra, a autora contextualiza as inter-relações entre os dois vectores na realidade socio-histórica portuguesa. A interpretação dos seus impactos na governação do campo da educação de adultos cruza-se com a análise diacrónica da especificidade da condição

\footnotetext{
${ }^{1}$ Doutoranda do Instituto de Educação, Universidade do Minho. E-mail: rosanna@net.sapo.pt

${ }^{2}$ Equiparada a Assistente na Escola Superior de Educação - Instituto Politécnico do Porto (ESSE-IPP), Investigadora Colaboradora no inED - Centro de Investigação e Inovação em Educação da ESSE-IPP, Investigadora Colaboradora no CIEd - Centro de Investigação em Educação da Universidade do Minho, Bolseira de Doutoramento da Fundação para a Ciência e a Tecnologia. E-mail: lilianaitlopes@gmail.com
} 
semiperiférica de Portugal no sistema-mundo, ao longo de um período onde se destacam os acontecimentos mais significativos para a delineação da realidade social, educativa e política portuguesa atual: a revolução de 25 de Abril de 1974 e a adesão à Comunidade Económica Europeia em 1986.

Na III Parte do livro traçam-se as tendências evolutivas das políticas educativas para o sector da educação de adultos em Portugal, destacando-se o papel central que a União Europeia desempenha na génese de "novas políticas de educação e formação de adultos" (p. 242), abrindo caminho à "transmutação das políticas e práticas da educação de adultos" no sentido de um "ethos instrumental de fundo" (p. 193).

Este livro oferece-nos uma visão diacrónica dos acontecimentos e produções políticas para o sector entre 1996 e 2006, desvelando criticamente os sentidos para o caminho ideológico seguido na definição de um novo mandato para a educação de adultos em Portugal, num movimento global concertado de reforma neoliberal do Estado e instrumentalização da educação e formação de adultos segundo lógicas concorrenciais, esvaziando o campo da sua dimensão democrática e democratizadora na construção social portuguesa. 